\title{
Jürgen Seefeldt, Ludger Syré, Portale zu Vergangenheit und Zukunft. Bibliotheken in Deutschland
}

Anne Saada

\section{OpenEdition}

\section{Journals}

Édition électronique

URL : http://journals.openedition.org/ifha/8658

DOI : $10.4000 /$ ifha. 8658

ISSN : 2198-8943

\section{Éditeur}

IFRA - Institut franco-allemand (sciences historiques et sociales)

Référence électronique

Anne Saada, « Jürgen Seefeldt, Ludger Syré, Portale zu Vergangenheit und Zukunft. Bibliotheken in Deutschland », Revue de l'IFHA [En ligne], Date de recension, mis en ligne le 01 février 2017, consulté le 24 septembre 2020. URL : http://journals.openedition.org/ifha/8658 ; DOI : https://doi.org/10.4000/ ifha.8658

Ce document a été généré automatiquement le 24 septembre 2020.

(CIFHA 


\title{
Jürgen Seefeldt, Ludger Syré, Portale $z u$ Vergangenheit und Zukunft. Bibliotheken in Deutschland
}

\author{
Anne Saada
}

\section{RÉFÉRENCE}

Jürgen Seefeldt, Ludger Syré, Portale zu Vergangenheit und Zukunft. Bibliotheken in Deutschland, Hildesheim, Zürich, New York: Georg Olms Verlag (4 édition, revue et augmentée), 2011, 128 p., 16,90€ 
Voici un petit ouvrage d'introduction utile consacré aux bibliothèques allemandes. Le compte-rendu en vient trop tard, car l'ouvrage en question a entre-temps été traduit en français, en 2014, et mis en ligne sur le site du Goethe Institut: Des portails vers le passé et le futur: les bibliothèques en Allemagne. Cependant, dans la mesure où il s'agit d'un document difficile à trouver si l'on ne connaît pas son existence, il n'est pas inutile d'en dire quelques mots, d'autant qu'il s'agit d'un outil indispensable pour qui a l'intention d'aller faire ses études en Allemagne ou d'y entreprendre des recherches.

L'ouvrage de Jürgen Seefeldt et de Ludger Syré constitue une présentation condensée de l'histoire, de l'organisation

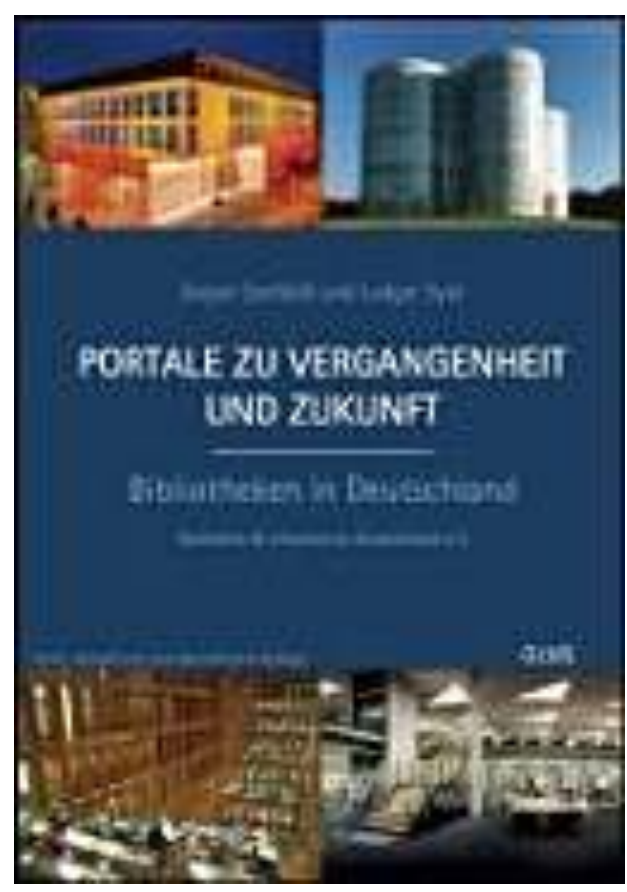
et de l'état actuel des bibliothèques allemandes. Il a été réalisé à la demande de l'association allemande des bibliothèques, le «Bibliothek \& Information Deutschland ", à l'occasion du $96^{\mathrm{e}}$ congrès mondial des bibliothécaires faisant partie de la Fédération internationale des associations de bibliothécaires et de bibliothèques (IFLA). Signe de son succès, l'ouvrage en est à sa quatrième édition depuis sa parution en 2003. Il avait connu une deuxième édition dès 2003, une troisième édition avec des remises à jour en 2007 et, plus récemment, cette édition de 2011, parue à l'occasion du centième anniversaire du congrès des bibliothécaires allemands. Autre signe de son succès, cet ouvrage a été traduit en anglais, en arabe et en chinois, ainsi qu'en plusieurs autres langues, dont le français, grâce au réseau international des instituts Goethe, membres du «Bibliothek \& Information Deutschland». La traduction française de 2014 se fonde sur l'édition de 2011, mais avec des données remises à jour en 2012 et 2013 par les auteurs et communiquées aux traductrices, Lise Rebout et Verena Majer.

Cet ouvrage constitue un utile complément à l'article d'introduction aux bibliothèques allemandes de Mareike König, "Les bibliothèques en Allemagne. Structures et stratégies de recherche " paru en 2011 dans le guide Faire de l'histoire en Allemagne, dirigé par Falk Bretschneider et Mareike König (voir IFHA 3, 2011).

\section{INDEX}

Index chronologique : Ouvrages transpériodiques

Thèmes : Manuels/Ouvrages généraux/Outils de travail, Histoire de la culture 
AUTEURS

ANNE SAADA

CNRS-UMR 8547 